\title{
Process Optimization of Astaxanthin Extraction from Antarctic kill (Euphausia superba) by subcritical $\mathrm{R} 134 \mathrm{a}$
}

\author{
Xiao Sui ${ }^{1, a}$, Rongyan Yue ${ }^{2, b}$, Lan Wang ${ }^{2, c}$, Yuqian Han ${ }^{2, d}$ \\ ${ }^{1}$ College of Life Science,Qingdao University,Qingdao 266071,China \\ ${ }^{2}$ College of Food Science and Engineering,Ocean University of China,Qingdao 266003,China, \\ asuixiaoqd@sina.com, ${ }^{b}$ yry86582359@126.com, ${ }^{c}$ wanlanouc@163.com, \\ hanyuqian@ouc.edu.cn,
}

Keywords: Antarctic kill (Euphausia superba), astaxanthin, Subcritical R134a, Response surface methodology, extraction.

Abstract. Subcritical 1, 1, 1, 2-tetrafluoroethane (R134a) extraction is a modern extraction technology in natural product perpartion. The optimized process of extracting astaxanthin from Antarctic kill (Euphausia superba) through subcritical R134a was systematically investigated in this work with respect to the key parameters including extraction pressure, extraction temperature and extraction time by the response surface methodology. Response surface analysis showed that the data came to a precise fitting to a second-order polynomial model. According to the results, the optimum operating conditions with $11 \mathrm{MPa}, 41^{\circ} \mathrm{C}$ and $40 \mathrm{~min}$ would increase the astaxanthin extraction rate to 93.2\%. The present study suggested the feasibility of our subcritical R134a extraction approach for isolating astaxanthin from such sources as Antarctic kill.

\section{Introduction}

Astaxanthin is a carotenoid that is widely present in crabs, fishes, some specific microalgaes, and fungi. It is a strong antioxidant exhibiting one or two orders of magnitude higher free radical antioxidant activity than beta-carotene and Vitamin E, respectively[1]. Astaxanthin is believed to suppress tumor, reduce blood lipid, boost immunity and to help the intellectual development[2]. Hence, it has found important applications in the nutraceutical, cosmetics, food and feed industries.

Antarctic kill (Euphausia superba) living in the southern ocean is a great number of Marine crustaceans. Because of high-fuocine, Antarctic kill can not be eaten directly. Then, Some works have shown that the Antarctic krill contains abundant astaxanthin, and it is a good source for natural astaxanthin[3].

Isolation of astaxanthin from marine shrimps relies on alkaline method, solvent extraction or supercritical carbon dioxide. The former approach involves large amounts of alkaline and acid chemicals which pose not only environmental problems but damage to astaxanthin too, and hence receives little interest now. The second popular way suffers solvent residue in the extracts and extracted substances, particularly considering that many organic solvents used are toxic. There have been some reports on supertitical carbon dioxide used for astaxanthin extraction from marine shrimps. According to X.C. Zhou et al. the optimal conditions included temperature at $80^{\prime} \mathrm{C}$, pressure at 45 $\mathrm{MPa}$, time of $2.5 \mathrm{~h}$ and flow rate at $20 \mathrm{~kg} / \mathrm{h}$ [4]. Another work by Andrea et al. showed that supercritical $\mathrm{CO}_{2}$ extraction of astaxanthin from Brazilian redspotted shrimp waste can be best achieved at $37 \mathrm{MPa}$ and $43^{\circ} \mathrm{C}[5]$. X. Q. Zhouand co-workers applied the same method to Hainan penacus orientalis with dichloromethane as entrainers, confirming that $35 \mathrm{MPa}$ and $60^{\circ} \mathrm{C}$ formed the optimised parameters[6]. Despite the fact that the supercritical $\mathrm{CO}_{2}$ approach is nontoxic and shows high extraction rate, it appears difficult to be deployed for commercial use as the high pressure up to $35 \mathrm{MPa}-45 \mathrm{MPa}$ typically required turned the method not economically viable and technologically challenging.

Subcritical1, 1, 1, 2-tetrafluoroethane ( $\mathrm{R} 134 \mathrm{a}$ ) represents an alternative solvent to supercritical $\mathrm{CO}_{2}$, but the working principle for extraction is quite close. It is particularly worth noting that this solvent allows much lower operating pressure thus overcoming the major barriers in the conventional method and rendering the new way much attention. Pedro C. Simoesfractionated deep-sea shark liver oil by 
subcritical $\mathrm{R} 134 \mathrm{a}$ at $6.0 \mathrm{MPa}$ and in the temperature range of $80^{\circ} \mathrm{C}$, in contrast to $25 \mathrm{MPa}$ and $60^{\circ}$ Cwhen using $\mathrm{CO}_{2}$ [7]. Clearly, R134a is more costly feasible. Here for the first time we applied subcritical R134a toAntarctic kill to extract astaxanthin. The objective of this work is to examine the feasibility of such an approach and further optimize the key parameters of the extraction process for possible commercialization in the future.

\section{Materials and Methods}

Materials. Antarctic kill(Euphausia superba )was supplied by Daishan Tongqu Aquatic Food Co., Ltd. Freeze dried tissue samples showed a low moisture concentration of around $6.7 \%$ and were subsequently mechanically crushed for homogeneous fine powders (particle size 120mesh). To avoid oxidation, the specimens were sealed into aluminium bags and stored in the fridge until use. Astaxanthin standard and R134a were purchased from Sigma (US, >96\%) and KLEA (UK, >99.9\%), respectively.

HPLC analysis of astaxanthin. (1) Extraction of astaxanthin: Extraction of astaxanthin was repeated a couple of time within $3 \mathrm{~h}$ from $1.0 \mathrm{~g}$ of specimen in $20 \mathrm{~mL}$ of dichloromethane. The solvent extract was filtered through a nylon membrane $(0.45 \mathrm{um})$ and washed using $\mathrm{NaCl}$ solution (4\%) before the dichloromethane layer was separated. (2)Saponification of astaxanthin esters: $1 \mathrm{~mL}$ of $\mathrm{NaOH}$ solution in methanol $(0.1 \mathrm{~mol} / \mathrm{L})$ was added to $5 \mathrm{~mL}$ of astaxanthin extract solvents to form mixture fluid which was condensed with flowing $\mathrm{N}_{2}$ gas to $5 \mathrm{~mL}$. The obtained products were then sealed for reaction at $4^{\circ} \mathrm{C}$ for $8 \mathrm{~h}$, following a filtration process through an organic membrane of $0.22 \mathrm{um}$. (3) HPLC detection method: The major operating parameters include Agilent HP1100 XDB $\mathrm{C}_{18}$ chromatographic column: $4.6 \times 250 \mathrm{~mm}, 5 \mu \mathrm{m}$; temperature: $30^{\circ} \mathrm{C}$; mobile phase: methane/ $\mathrm{MeCN}$ $=75: 25(\mathrm{~V} / \mathrm{V})$; detection wavelength: $483 \mathrm{~nm}$; flow rate: $1 \mathrm{~mL} / \mathrm{min}$; and feed volume: $20 \mu \mathrm{L}$. Dissolving $0.01 \mathrm{~g}$ of astaxanthin standard into $100 \mathrm{~mL}$ of dichloromethane formed standard solution that was diluted by methane/MeCN $(75 / 25, \mathrm{~V} / \mathrm{V})$ solvent to varied concentrations, from $0.4 、 1 、 2$ 、 4、6、 8 to $10 \mu \mathrm{g} / \mathrm{mL}$. The standard solution was analysed through HPLC and the peak area (y) was plotted against the astaxanthin concentration $(x)$ according to the standard equation: $y=229.58 x+8.174$ $\left(\mathrm{R}^{2}=0.9996\right)$ with $\mathrm{x}$ in the range of $0.4-10 \mu \mathrm{g} / \mathrm{mL}$. Content of astaxanthin in specimen $(\mathrm{M}, \mathrm{mg} / \mathrm{g})$ can be calculated through the following formula : $M=(x \times V) /(m \times 1000)$, where $x$ is calculated astaxanthin concentration from the standard equation $(\mu \mathrm{g} / \mathrm{ml}) ; \mathrm{V}$ is volume of solution $(\mathrm{ml}) ; \mathrm{m}$ is mass of specimen (g).

Astaxanthin extraction by subcritical R134a. The extraction experiments were performed according to the method described by Xiao Sui et al [8]. Antarctic kill power of $20 \mathrm{~g}$ were loaded into the extraction cell that was subsequently placed in a heated bath with controlled temperature. The subcritical R134a was introduced into the extraction cell by an air-driven pump at the extraction pressure controlled by a back-pressure regulator. The flow rate of $\mathrm{R} 134 \mathrm{a}$ was regulated by a rotameteran and was fixed at $8 \mathrm{~g} / \mathrm{min}$. Astaxanthin containing R134a fluid was depressurized before collected, then extracts was retained in Collector. Received extracts were weighed for further analysis of astaxanthin regarding its content.

Extraction rate. Extraction rate of astaxanthin was detected according Eq. (1).

$$
\text { Extraction rate }(\%)=\left[\left(\mathrm{G}_{1} \times \mathrm{M}_{1}\right) /\left(\mathrm{G}_{0} \times \mathrm{M}_{0}\right)\right] \times 100 \%
$$

Where $\mathrm{G}_{0}$ is the mass of Antarctic kill power ( $\mathrm{g}$ ); $\mathrm{M}_{0}$ is the content of astaxanthin in Antarctic kill power $(\mathrm{mg} / \mathrm{g}) ; \mathrm{G}_{1}$ is the mass of extracts $(\mathrm{g}) ; \mathrm{M}_{1}$ is the content of astaxanthin in extracts $(\mathrm{mg} / \mathrm{g})$.

Experimental design of the response surface. Based on the results from individual effect, the most important factors, extraction pressure, extraction temperature and extraction time were optimized by deploying RSM. In this way, the relationship between the input variables and response values can be established. Coded levels are listed in Table 1. Using the following second-order polynomial equation, the behaviour of the response surface for extraction rate as the response function 
was examined. Minitab software was used to calculate all coefficients for the response surface model derived by fixing one variable but confining the rest to a specific range.

$$
Y=\beta_{0}+\sum_{i=1}^{3} \beta_{i} X_{i}+\sum_{i=1}^{3} \beta_{i i} X_{i}{ }^{2}+\sum_{i \neq j=1}^{3} \beta_{i j} X_{i} X_{j}
$$

Where $Y$ is the extraction rate, $\beta_{0}$ is the constant coefficient, $\beta_{\mathrm{I}}, \beta_{\mathrm{ii}}$ and $\beta_{\mathrm{ij}}$ are interaction coefficient of linear, quadratic and the second-order terms, respectively, $X i$ and $X j$ are variables.

Table 1 Uncoded and coded independent variables used in RSM design

\begin{tabular}{ccccc}
\hline \multirow{2}{*}{ Symbols } & \multirow{2}{*}{ Independent variable } & \multicolumn{3}{c}{ Coded levels } \\
\cline { 3 - 5 } & Pressure $(\mathrm{MPa})$ & 8 & 0 & 1 \\
\hline$X_{1}$ & Temperature $\left({ }^{\circ} \mathrm{C}\right)$ & 30 & 40 & 12 \\
$X_{2}$ & Time $(\min )$ & 30 & 40 & 50 \\
$X_{3}$ & &
\end{tabular}

\section{Results and Discussion}

Experimental results from the response surface. In the present study, the Box-Bhenken Design was employed and the generated results were tabulated in Table 2. Aided by Minitab, a fitted response surface is generated,

$$
Y(\%)=89.3333+5.45 X_{1}+2.1375 X_{2}+9.2375 X_{3}-2.9417 X_{1}^{2}-7.7667 X_{2}^{2}-6.9167 X_{3}^{2}+0.125 X_{1} X_{2^{-}}
$$
$1.975 X_{1} X_{3}+1.05 X_{2} X_{3}$

Table 2 Experimental points of the Box-Behnken design and the experimental data

\begin{tabular}{cccccc}
\hline No & $X_{1}$ & $X_{2}$ & $X_{3}$ & $\begin{array}{c}\text { Observed } \\
\text { value }\end{array}$ & $\begin{array}{c}\text { Predicted } \\
\text { value }\end{array}$ \\
\hline 1 & -1 & -1 & 0 & $71.6 \%$ & $71.2 \%$ \\
2 & 1 & -1 & 0 & $81.7 \%$ & $81.8 \%$ \\
3 & -1 & 1 & 0 & $75.3 \%$ & $75.2 \%$ \\
4 & 1 & 1 & 0 & $85.9 \%$ & $86.3 \%$ \\
5 & -1 & 0 & -1 & $62.4 \%$ & $62.8 \%$ \\
6 & 1 & 0 & -1 & $77.8 \%$ & $77.6 \%$ \\
7 & -1 & 0 & 1 & $85.1 \%$ & $85.2 \%$ \\
8 & 1 & 0 & 1 & $92.6 \%$ & $92.2 \%$ \\
9 & 0 & -1 & -1 & $64.3 \%$ & $64.3 \%$ \\
10 & 0 & 1 & -1 & $66.8 \%$ & $66.5 \%$ \\
11 & 0 & -1 & 1 & $80.4 \%$ & $80.7 \%$ \\
12 & 0 & 1 & 1 & $87.1 \%$ & $87.0 \%$ \\
13 & 0 & 0 & 0 & $89.2 \%$ & $89.3 \%$ \\
14 & 0 & 0 & 0 & $89.3 \%$ & $89.3 \%$ \\
15 & 0 & 0 & 0 & $89.5 \%$ & $89.3 \%$ \\
\hline
\end{tabular}


Table 3 ANOVA table for the fitted quadratic polynomial model

\begin{tabular}{cccccc}
\hline Source & $\begin{array}{c}\text { Degree of } \\
\text { freedom }\end{array}$ & $\begin{array}{c}\text { Sum of } \\
\text { squares }\end{array}$ & $\begin{array}{c}\text { Mean } \\
\text { square }\end{array}$ & F-value & P-value \\
\hline Model & 9 & 1361.32 & 151.258 & 745.72 & $<0.001$ \\
Residual & 5 & 1.01 & 0.203 & & \\
Lack of fit & 3 & 0.97 & 0.323 & 13.82 & 0.068 \\
Error & 2 & & & & \\
Total & 14 & & $\mathrm{R}^{2}=0.9993$ & $\mathrm{R}^{2} \mathrm{Adj}=0.9886$ & \\
\hline
\end{tabular}

Table 3 shows a Fisher F-value of 745.72 and a p-value that is smaller than 0.001 , indicating that the model derived and the associated terms are significant. Lack of fit is negligible as its value is larger than 0.05 . The value of adjusted coefficient of determination $\left(\mathrm{R}_{\text {Adj }}^{2}\right)$ was calculated to be 0.9886 , implying that $98.86 \%$ of experimental results agreed with the predicted data. In other words, the model proves significant and adequate to fit the relationship between the response and input variable.

Table 4 Estimated coefficients of second order response model

\begin{tabular}{cccccc}
\hline $\begin{array}{c}\text { Coefficient } \\
\text { terms }\end{array}$ & $\begin{array}{c}\text { Degree of } \\
\text { freedom }\end{array}$ & $\begin{array}{c}\text { Regression } \\
\text { coefficient }\end{array}$ & STD & T-value & P-value \\
\hline Constant & 1 & 89.3333 & 0.002600 & 343.562 & $<0.001$ \\
$X_{1}$ & 1 & 5.45000 & 0.001592 & 34.227 & $<0.001$ \\
$X_{2}$ & 1 & 2.13750 & 0.001592 & 13.424 & $<0.001$ \\
$X_{3}$ & 1 & 9.23750 & 0.001592 & 58.014 & $<0.001$ \\
$X_{1}{ }^{2}$ & 1 & -2.94170 & 0.002344 & -12.551 & $<0.001$ \\
$X_{2}{ }^{2}$ & 1 & -7.76670 & 0.002344 & -33.137 & $<0.001$ \\
$X_{3}$ & 1 & -6.91670 & 0.002344 & -29.510 & $<0.001$ \\
$X_{1} X_{2}$ & 1 & 0.12500 & 0.002252 & -0.5550 & 0.603 \\
$X_{1} X_{3}$ & 1 & -1.9750 & 0.002252 & -8.7710 & $<0.001$ \\
$X_{2} X_{3}$ & 1 & 1.0500 & 0.002252 & 4.4663 & 0.006 \\
\hline
\end{tabular}

Table 4 shows the significance of the regression coefficients and good significance can be confirmed for the constant term, the linear terms including $X_{1}, X_{2}$ and $X_{3}$, the quadratic terms that include $X_{1}^{2}, X_{2}^{2}$ and $X_{3}^{2}$, and the interaction terms including $X_{1} X_{3}$ and $X_{2} X_{3}$, but not for the rest.

Response surface plots. 3D response surface plots can better present the influence of the individual variableson the extraction rate. In Fig. 1, the specific surface areas are plotted against two variables whereas the third was maintained unchanged. In this way we can attain a second-order polynomial equation that help to create the response surface so that to find out the optimum extraction conditions. Applying the Minitab software package to the results from the extraction experiments allows regression models and Fig.1 illustrated the response surface. 


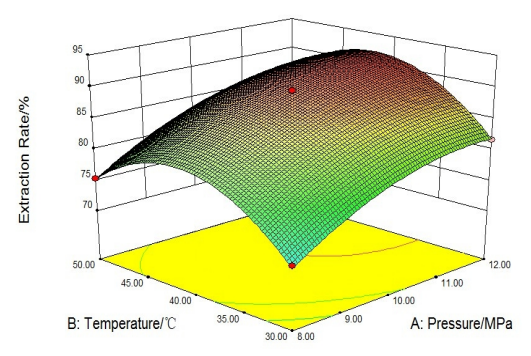

(a)

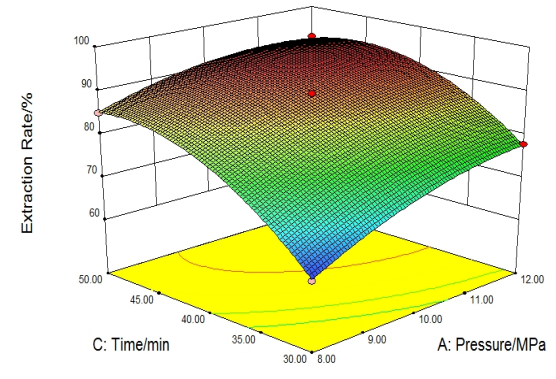

(b)

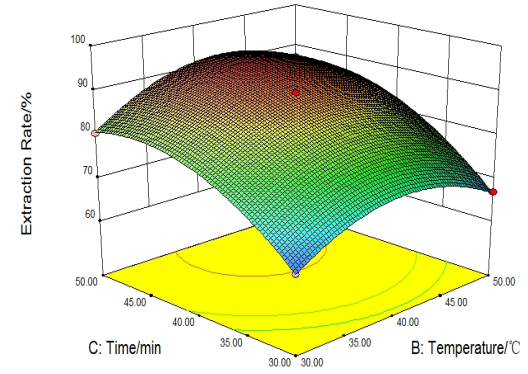

(c)

Fig.1Response surface plot for extraction rate (\%):

(a) the effect of pressure and temperature on extraction rate (time level: 40min); (b) the effect of pressure and time on extraction rate (temperature level: $40^{\circ} \mathrm{C}$ ); (c) the effect of temperature and time on extraction rate (pressure level: $10 \mathrm{MPa}$ )

Effect of pressure . The Fig.1-a and 1-b indicated the important role of pressure that played in affecting the extraction rate. If all other variables are fixed, the extraction rate increases with pressure in the early stage. The optimized pressure through response surface methodology is $11 \mathrm{MPa}$ when the extraction rate reaches its maximum value. This can be explained by the polarisability parameter $\left(\pi^{*}\right)$ theory put forward by Kamlet who demonstrated that there is roughly a linear relationship between $\pi^{*}$ and the density of solvent[9]. Abbott et al. further studied the relationship between the $\pi^{*}$ value of $\mathrm{R} 134 \mathrm{a}$ and pressure and it was revealed that the $\pi^{*}$ value in the liquid region increases with pressure linearly, implying a higher density of R134a with increasing pressure[10]. Therefore, increasing pressure can promote the dissolution of astaxanthin and thus the extraction rate.

At higher pressure than $11 \mathrm{MPa}$, the pressure effect on the extraction rate becomes less noticeably. It can be ascribed to the high viscosity of R134a fluid that increases with pressure and tends to prevent the spreading of solute to the solvent and decrease the extraction rate.

Effect of temperature. The effect of temperature on astaxanthin extraction is displayed in Fig.1-a and 1-c. Theoretically, the extraction rate favours higher temperature when the pressure remains constant. The result in this study is in accordance with what is expected, that is, the extraction increases with temperature. The solubility of solute relies on the competition between the density of subcritical fluid and the vapour pressure. High temperature reduces the density and worsens the solubility, but on the other hand, it also increases the vapour pressure and thus contributes to better solubility. The solubility of astaxanthin in R134a fluid is found to decrease with increasing temperature while its volatility increases with temperature. For the temperature from $30^{\circ} \mathrm{C}$ to $40^{\circ} \mathrm{C}$, the extraction rate is increased. In this region, the solubility is largely governed by the solute vapour pressure. Furthermore, it is related to the faster diffusion of due to the increased temperature and mass transfer rate. Brunner has suggested that the volatility, mass transfer rate as well as extraction rate all benefited from increasing temperatures[11]. To the present case, it is therefore concluded that higher extraction temperatures improve vapour pressure, mass transfer rate and extraction rate of astaxanthin.

However, at temperatures higher than $40^{\circ} \mathrm{C}$, the extraction decreases instead. This can be understood by considering the density of subcritical solvent, a factor that is dominated by temperature and would decrease when temperature is elevated. Therefore, the reduced dissolution of R134a is induced. In addition, higher temperature would oxidize astaxanthin and consequently the extraction rate becomes worse.

Effect of time. For the sake of optimized extraction rate, it is important to maximize the contact between subcritical R134a and solute. There are many factors that contribute to the contact, including extraction time and the flow rate[12]. Fig.1-b and 1-c present their results about the effect of time on the extraction rate. It is evident that the extraction rate increases as a result of extended process time and the best extraction rate is observed for the time period of 40 min when the flow rate of R134a was fixed at $8 \mathrm{~g} / \mathrm{min}$. This observation can be attributed to the improved extraction efficiency due to that the contact time between R134a and astaxanthin becomes longer and the consumption of R134a is 
increased. The extraction rate does not increase any more, if the extraction time is further extended, indicating that under these optimal conditions astaxanthin has been completed extracted and extending the process time does help the extraction rate.

Verification of optimized conditions. The extraction condition using subcritical R134a is truly optimized only if the extraction rate reaches the maximum value and these optimum conditions can be found by differentiating the regression equation. Our calculations showed the values for $X_{1}, X_{2}$ and $X_{3}$ to be $0.7374,0.1919$ and 0.5758 , respectively, corresponding to an extraction pressure of $11.5 \mathrm{MPa}$, the extraction temperature of $41.2^{\circ} \mathrm{C}$ and extraction time of $39.6 \mathrm{~min}$ with a high extraction rate of $94.19 \%$. Reasonably, we set the pressure, temperature and time at $11 \mathrm{MPa}, 41^{\circ} \mathrm{Cand} 40 \mathrm{~min}$, respectively as the optimum conditions. Three independent experimental runs gave rise to Table 5 where the extraction rate is $93.2 \%$ in average and quite close to the predicted value. It means response surface methodology functions well for the process optimization of astaxanthin extraction from Antarctic kill by subcritical R134a.

Table 5 Test of optimum condition of extraction

\begin{tabular}{lcccc}
\hline \multirow{2}{*}{$\begin{array}{c}\text { Extraction } \\
\text { rate }(\%)\end{array}$} & \multicolumn{3}{c}{ Experiment No. } & $\begin{array}{c}\text { Average } \\
\text { value }\end{array}$ \\
\cline { 2 - 4 } & 92.91 & 2 & 3 & 93.20 \\
\hline
\end{tabular}

\section{Conclusions}

By employing response surface methodology to model the effect of the independent process variables on the astaxanthin extraction from Antarctic kill (Euphausia superba) by subcritical R134a, the optimum extraction environments were established. The extraction pressure, temperature, time were determined to be, $11 \mathrm{MPa}, 41^{\circ} \mathrm{C}, 40 \mathrm{~min}$, respectively. The associated high extraction rate of $93.2 \%$ provided strong evidence of the feasibility of our R134a approach in extracting astaxanthin. In contrast to prior studies where supercritical $\mathrm{CO}_{2}$ was used to extract astaxanthin from marine shrimps, the pressure required by subcritical R134a extraction in the present study is seriously lowered and we believe our approach holds great promise for wide applications in the astaxanthin extraction.

\section{References}

[1] Miki W.. Pure Appl. Chem. ,Vol. 63(1) (1991), p.141 146.

[2] Guerin M., Huntley M. E., Olaizola M., et al. Trends in Biotech., Vol. 21(5) (2003), p. $210 \sim 216$.

[3] Allahpichay I., Shimizu C., Bull. Japanese Soc. Sci. Fish, Vol. 51(1985), p.945 951.

[4] Xiangchi Zhou, Biqian Liu, Yongjiang Lou, et al. Reservoir Fisheries (in chinese). Vol.24(5)(2004), p. 21 23.

[5] Andrea P. Sanchez-Camargo, Hugo A. Martinez-Correa, Losiane C. Paviani, et al. The Journal of Supercritical Fluids, Vol. 56 (2) 2011,p.164 173.

[6] Xueqing Zhou, Yuhong Feng, Yanli Xie, et al. Natural Science Journal of Hainan University(in Chinese), 2011Vol. 3(1)(2011), P.29 32.

[7] Pedro C. Simoes, Owen J. Catchpole. Ind. Eng. Chem. Res., Vol. 41(2) (2002), p. 267 276.

[8] Xiao Sui, Xiaomei Feng, Rongyan Yue, et al. Advanced Material Research, Vols.1033-1034(2014), p.717-723.

[9] Kamlet M. J., Abboud J. L. M, Abraham M. H., et al. The Journal of Organic Chemistry, Vol. 48(17) (1983), p. 2877 2887.

[10] Andrew P. Abbott, Christopher A. Eardley, James E. Scheirer. J. Phys. Chem. B, Vol. 103(41) (1999), p. 8790 8793. 
[11]Brunner G.. Journal of Supercritical Fluids, Vol.13 (1-3) (1998), p. 283 301.

[12] Pourmortazavi S.M., Hajimirsadeghi S.S.. Journal of Chromatography A, Vol.1163 (1-2) 2007, p. 2 24. 